\title{
Two models of inventory control with supplier selection in case of multiple sourcing: a case of Isfahan Steel Company
}

\author{
Masood Rabieh $^{1} \cdot$ Mohammad Ali Soukhakian $^{2} \cdot$ Ali Naghi Mosleh Shirazi ${ }^{2}$
}

Received: 13 August 2015/Accepted: 23 February 2016/Published online: 24 March 2016

(c) The Author(s) 2016. This article is published with open access at Springerlink.com

\begin{abstract}
Selecting the best suppliers is crucial for a company's success. Since competition is a determining factor nowadays, reducing cost and increasing quality of products are two key criteria for appropriate supplier selection. In the study, first the inventories of agglomeration plant of Isfahan Steel Company were categorized through VED and ABC methods. Then the models to supply two important kinds of raw materials (inventories) were developed, considering the following items: (1) the optimal consumption composite of the materials, (2) the total cost of logistics, (3) each supplier's terms and conditions, (4) the buyer's limitations and (5) the consumption behavior of the buyers. Among diverse developed and tested models-using the company's actual data within three pervious years-the two new innovative models of mixed-integer non-linear programming type were found to be most suitable. The results of solving two models by lingo software (based on company's data in this particular case) were equaled. Comparing the results of the new models to the actual performance of the company revealed 10.9 and $7.1 \%$ reduction in total procurement costs of the company in two consecutive years.
\end{abstract}

Keywords Inventory control - Supplier selection · Multiple sourcing $\cdot$ Mathematical models

Masood Rabieh

M_Rabieh@sbu.ac.ir

1 Department of Industrial Management, Shahid Beheshti University, Tehran, Iran

2 Department of Management, Shiraz University, Shiraz, Iran

\section{Introduction}

Supplier selection is turning to become one of the crucial decisions in operations management area for many companies. Nowadays that competition plays a major role in business, two factors, namely, cost reduction and increase in quality of products, are keys to success of a company. Attaining these two factors is heavily dependent on having appropriate suppliers. Therefore, selecting appropriate suppliers can increase the competitiveness of a business.

The main cost of a product is mostly dependent on the cost of raw material and component parts in most industries (Ghodsypour and O'Brien 2001). Under such a condition the raw material supply and its inventory control can play a key role in the efficiency and effectiveness of a business and have a direct impact on cost reduction, profitability and its flexibility. Regarding supplier selection, there are two general situations:

Single sourcing A situation in which there is no constraint and a single supplier of an item is able to satisfy all requirements of the buyer.

Multiple sourcing In this situation there are many suppliers of a required item, but no single suitable supplier can satisfy all requirements of the buyer. Thus, the buyer must choose "an appropriate set of suitable supplies" to work with (Ghodsypour and O'Brien 1998).

Considering many factors such as variations in price, terms and conditions, quality, quantity, transportation costs and distances, etc. of each supplier, the multiple sourcing situations usually involves taking complex decisions.

While there is a paucity of research that takes into account different aspects of this complex decision situation, only a limited number of mathematical models have been proposed for such decisions. Many of the proposed 
models consider "net price" as the main factor, a few of them consider "the total costs of logistics".

The present study investigates the issue of multiple sourcing and proposes mathematical models based on considering factors such as net price, transportation costs, inventory costs and shrinkage problems.

The rest of this paper is organized as follows. In "Background" section literature review is presented. In "The situation" section, the case study is described. The mathematical formulating of problem is presented in "Formulating the models" section. Data collection and parameters are described in "Parameters of model" section. Computational result is presented in "Model runs and results" section and finally, some concluding remarks are given in "Discussion and conclusion" section.

\section{Background}

Supplier selection literature may generally be divided into two areas: First, descriptive, survey type approaches and, second, quantitative modeling methods. In the first area, the researches of Dickson (1966) and Weber et al. (1991) should be mentioned as the most comprehensive ones. Dickson has identified and summarized a number of criteria that purchasing managers consider for supplier selection. In his view, the most important criteria are quality, delivery, and the performance history of the supplier. Weber et al. (1991) in a review of 74 articles on supplier selection criteria, found that the most important factor is net price, yet, they suggested that supplier selection is dependent on a multitude of factors with different priorities, depending on the particular purchasing situation.

In the second area, which is more relevant to this article, a few number of fine research attempts should be mentioned here.

Benton (1991) applied Lagrange relaxation to develop a non-linear program for supplier selection under various conditions including multiple suppliers, multiple items, resource limitations and quantity discount. Ghodsypour and O'Brien (1997) suggested integrated analytical hierarchy process (AHP) with mixed integer programming to develop a decision support system (DSS). Their objective was to reduce the number of suppliers. Ghodsypour and O'Brien (1998) also developed a model to take into account both qualitative and quantitative factors. This approach was based on the integration of AHP and linear programming model. In a further development Ghodsypour and O'Brien (2001) presented a mixed integer non-linear programming model to solve the multiple sourcing problems. Their model takes the total cost of logistics into consideration. Kumar et al. (2004) advised a fuzzy goal programming approach to solve the vendor selection problem in case of multiple objectives. Chen et al. (2006) presented a fuzzy decision making approach to solve the supplier selection problem. They proposed linguistic values to evaluate the ratings for a number of quantitative and qualitative factors including quality, price, flexibility, and delivery performance. Their model shown to be very good tool for supplier selection decision making situation. Basnet and Leung (2005) investigated the problem of supplier selection considering the lot-sizing. Amid et al. (2006) represented multi objective linear programming model to supplier selection. Lin and Chang (2008) propose mixed-integer programming and fuzzy TOPSIS approach to solve the supplier selection problem. Aissaouia et al. (2007) have extended previous survey papers by presenting a literature review that covers the entire purchasing process and covers internet-based procurement environments. In the mentioned work they have focused especially on the final selection stage that consists of determining the best mixture of vendors and allocating orders among them so as to satisfy different purchasing requirements. Also, they have concentrate mainly on works that employ operations research and computational models. Farzipoor saen (2007) has considered widespread application of manufacturing philosophies such as just-in-time (JIT), emphasis has shifted to the simultaneous consideration of cardinal and ordinal data in supplier selection process and proposed an innovative method, which is based on imprecise data envelopment analysis (IDEA) to selected the best suppliers in the presence of both cardinal and ordinal data. Ustun and Aktar Demirtas (2008) have recommended an integrated approach of analytic network process (ANP) and multi-objective mixed integer linear programming (MOMILP) for supplier selection problem. Their approach considers both tangible and intangible factors in choosing the best suppliers and defines the optimum quantities among selected suppliers to maximize the total value of purchasing (TVP), and to minimize the total cost and total defect rate and to balance the total cost among periods. Soukhakian et al. (2007) developed a model based on the Ghodsypour and O'Brien (2001) model. The contribution of the developed model is compared with basic the basic model which consider limitations such as integer number of orders and minimum assigned order quantity to each supplier. Due to the complexity of model and its non-linearity, the model is solved by genetic algorithm. Rabieh et al. (2008) developed a new model based on the Ghodsypour and O'Brien (2001) model for a real case of the agglomeration unit of Isfahan Steel Company. In this model assume that some suppliers of iron concentrate in have to cover the inventory in turn during each ordering cycle $(T)$, while other suppliers of iron ore deliver their shipments simultaneously. In end, the nonlinear model is solved by LINGO 8 software. Jafarnezhad et al. (2009) introduced a fuzzy decision making approach 
for supplier selection problem in case of single sourcing. In this research, the fuzzy TOPSIS method was developed for ranking and selecting suppliers. At the end, a numerical example was introduced for showing performance of the developed method. Wu and Blackhurst (2009) presented a supplier selection and evaluation method based on an extension of data envelopment analysis (DEA) that can efficiently evaluate suppliers. Kuo and Lin (2012) introduced an integrated approach of analytic network process (ANP) and data envelopment analysis (DEA) in solving supplier selection problem. Their model also considered green indicators due to environmental protections issues. Finally, Mendoza and Ventura (2012) presented two mixed integer nonlinear programming models to select the best suppliers and determine order quantities. Their research integrated the issues of inventory management and supplier selection. Rao et al. (2013) developed a new approach to design a multi-echelon, multi-facility, and multi-product supply chain in uncertain environment in fuzzy form. In this research, a mixed integer programming was formulated at strategic level and a non-linear programming model was presented in tactical level. In the tactical level, inventory control of raw material of suppliers was considered (Table 1).

\section{The situation}

The agglomeration unit of Isfahan Steel works - one of the largest steel manufacturing firms in the ME region located in central Iran-is the case studied in this research. The main task of this unit is to agglomerate different kinds of raw materials in specific proportions. Most of the raw materials come from different quarries and plants scattered all over the country. The materials are bought and transported to the works mainly via railroads and sometimes by trucks in distances even up to $1300 \mathrm{~km}$. The functional and financial importance of each required raw materials for agglomeration unit found to be different in nature. So, as the first step, a classification of inventory items should have been curried out prior to actual modeling. The following three popular classification methods, so called selective inventory control techniques, are usually applied for grouping inventory items:

ABC analysis, classifies items in terms of annual financial requirement.

VED analysis, classifies items in terms of their functional importance (Vital, Essential, Desirable).

FNS analysis, classifies items in terms of their movement speed (Fast, Normal, Slow; Nair 2002).

Using $\mathrm{ABC}$ and VED methods, the inventory items of agglomeration plant were analyzed, and iron ore and iron concentrate were found to be the most important raw materials respectively. Thus, modeling in this study was focused around the purchasing and supply of these two items.

Iron concentrate is a supplementary material which is very similar to iron ore in appearance and should be mixed with iron ore in agglomeration process. Since it contains more Fe; its price is much higher than iron ore. However, to obtain a desired and consistent quality of the agglomeration process output, a right percentage of these two materials should be mixed together each time. The needed iron ore and concentrate for agglomeration plant is purchased from five different suppliers, none of which has the sufficient capacity to supply the whole annual requirements. Furthermore, there are some quality variations in their products and each supplier has its own supply characteristics.

The developed models in this study take into account such variations, and are formulated in a way to obtain a right combination of the raw materials in one hand, and minimize the total inventory costs in the other.

\section{Formulating the models}

\section{Defining model parameters and variables}

Before describing the model, the pertaining parameters and variables are defined as follows:

\section{Decision variables}

$Q$ : Ordered quantity to all suppliers in each period. $Q_{i}$ : Ordered quantity to $i$ th supplier in each period.

$X_{i}$ : Percentage of $Q$ assigned to $i$ th supplier.

$$
Y_{i}= \begin{cases}1 & \text { if } X_{i}>0 \\ 0 & \text { if } X_{i}=0\end{cases}
$$

\section{Parameters}

$D$ : Annual iron ore and concentrate demand (in term of tons).

$T$ : The length of each period.

$T_{i}$ : Part of the period in which the lot of $i$ th supplier $\left(Q_{i}\right)$ is used.

$n$ : Number of suppliers

$C_{i}$ : Annual capacity of the $i$ th supplier to supply raw material.

$C_{t i}$ : Transportation cost for $i$ th supplier per unit of raw material. 


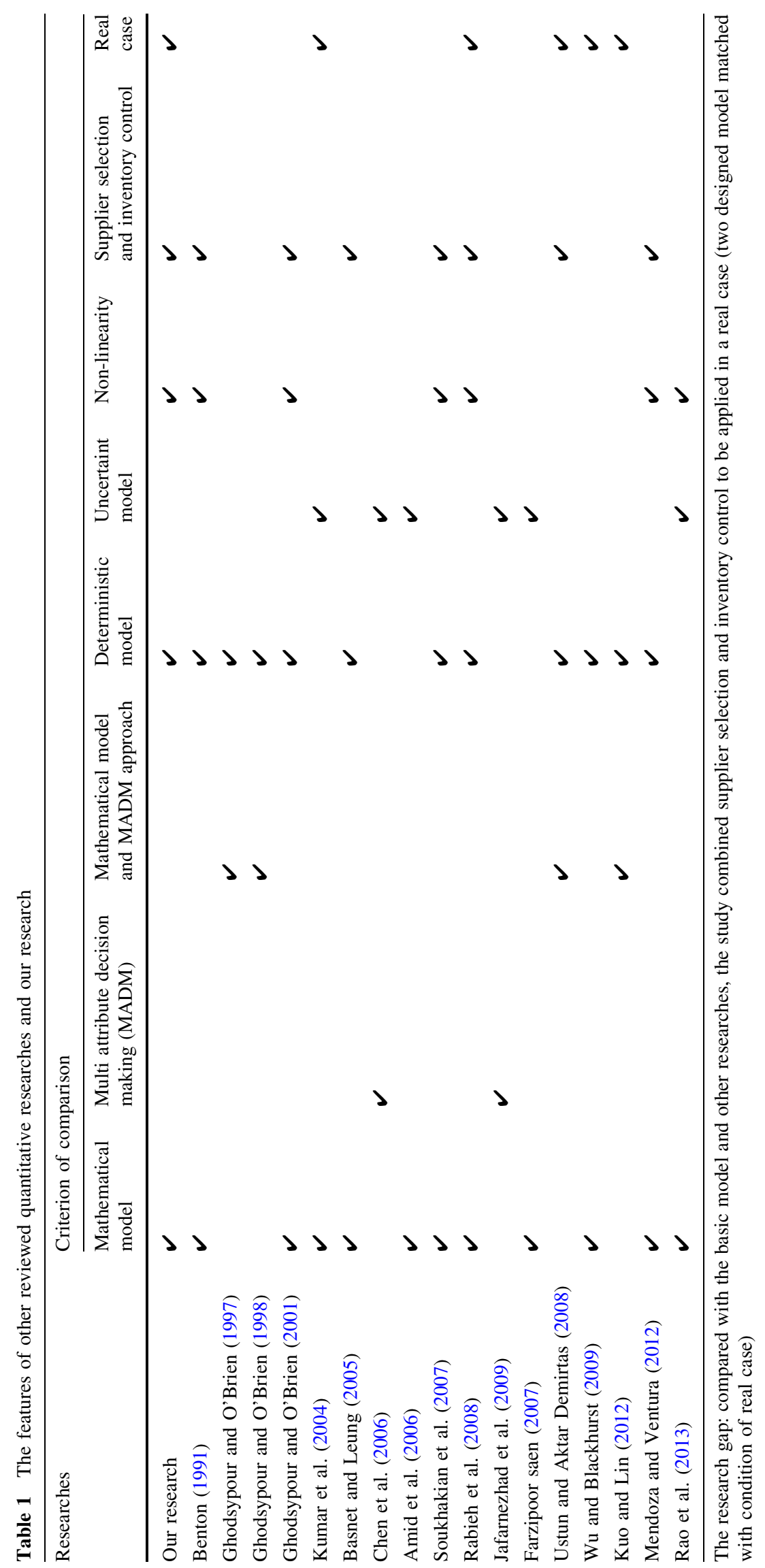


$r$ : Inventory holding cost rate.

$A_{i}$ : Ordering cost of $i$ th supplier's raw material.

$P_{i}$ : Selling price of $i$ th supplier's raw material.

$h_{i}$ : Percentage of moisture in the item of the $i$ th supplier.

$D^{\prime}$ : Speed of material consumption.

$P^{\prime}$ : Speed of receiving materials.

SS: Safety stock.

$\mathrm{SS}_{i}$ : Safety stock of the $i$ th supplier's item.

$$
\beta_{i}=\left(P_{i}+C_{t i}\right) \quad \text { and } \quad \alpha_{i}=\left(1-\frac{D_{i}^{\prime}}{P_{i}^{\prime}}\right)
$$

Other parameters and variables will be described later.

\section{The basic assumptions}

- Constant annual demand (D)

- Infinite raw materials storage space

- Stable prices over the year

- Gradual receiving and consumption of raw materials

- Stable safety-stock levels

- Stock-out is not allowed.

\section{Graphical explanation of models}

\section{The basic model}

The basic model is built following the approach and assumptions of Ghodsypour and O'Brien (2001) model. This model assumes instant, in-simultaneous order receives from different suppliers and gradual consumption of the materials. Figure 1 shows the behavior of inventory levels of an item under the assumptions of this model.

In Fig. 1, total order cycle $(T)$ is equal to the sum of order cycles of every supplier $\left(T_{i}\right)$ and at the time one supplier's inventory is used up, the next supplier's shipment would arrive in.

In general, this model is applicable to situations where, the quality specification of receiving items from different sources is identical. And no mixing of different items is required.

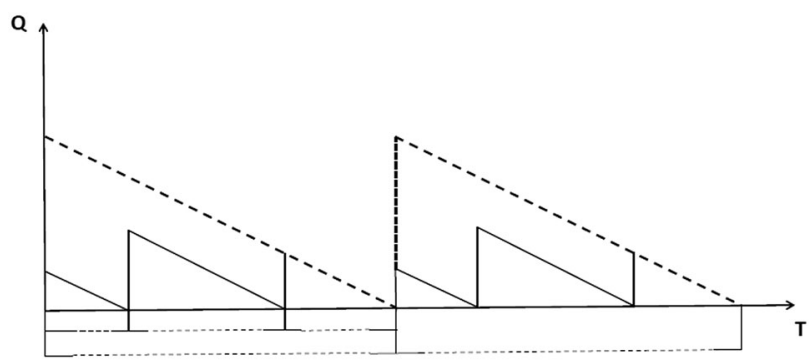

Fig. 1 Inventory behavior in the basic model

\section{The new models}

Because of the need for mixing iron ore and concentrating on the agglomeration process, the basic model couldn't be applied for the current situation. Furthermore, the inventory supply is not instantaneous, but placed orders are shipped gradually. So, the basic model had to be manipulated to fit the situation correctly. Two slightly different possibilities were considered as shown in Figs. 2 and 3.

Model A The two supplier of iron concentrate in Model A ( $Q_{4}$ and $Q_{5}$ ) have to cover the inventory in turn during each ordering cycle $(T)$, while the three suppliers of iron ore deliver their shipments simultaneously.

Model B In Model B all suppliers send their shipments simultaneously, therefore, they are under less pressure to keep up with a tight delivery schedule.

Comparing with The basic model, at the first glance, one may expect a rise in average inventory in Models A and B, which leads to an increase in total annual carrying costs as a result. But, as we will see later, the inherent flexibility of the new models paves the way for formulating more effective ordering policies. This would prevent such increase in costs to materialize in practice.

Obviously, Models A and B were formulated for different purchasing behaviors. The formulation process of both models is very similar to each other. The slight differences actually are in formulating the carrying cost in objective function and in the quality constraints of the models. So, we skip from presenting such details here, and continue our model formulation only for Model A.

\section{Formulating the objective function}

Because of the objective function of this model is formed from inventory related costs such as the purchasing price,

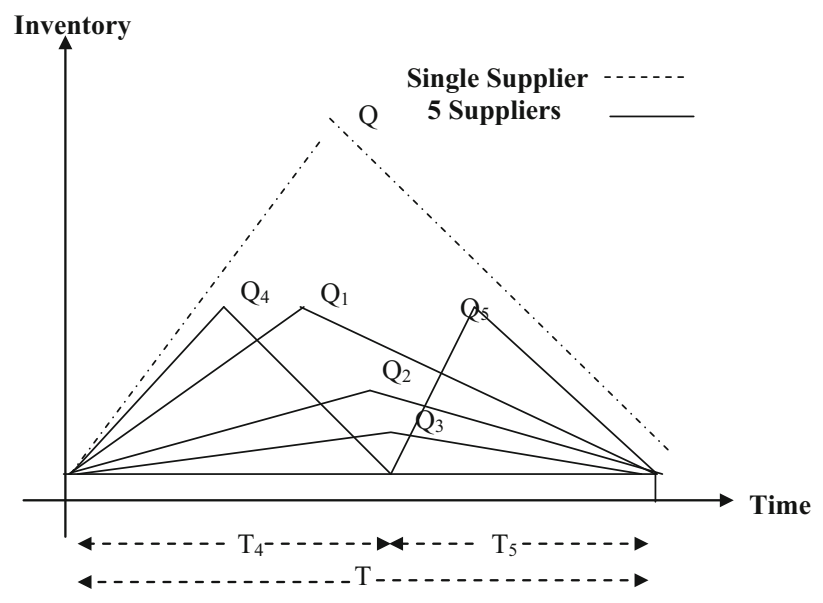

Fig. 2 Inventory behavior in Model A 


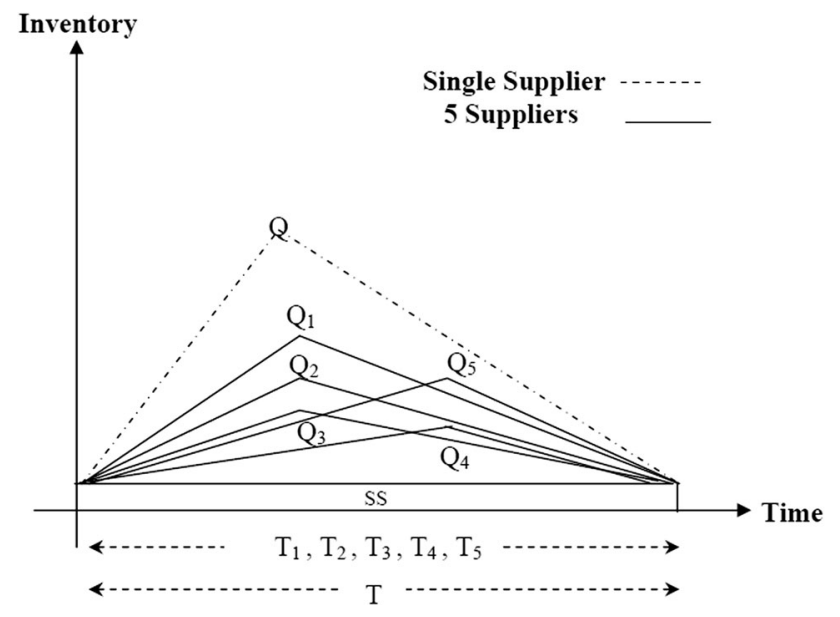

Fig. 3 Inventory behavior in Model B

transportation costs, carrying and ordering costs, shrinkage cost, it is a minimizing type objective function. The shrinkage cost is mainly related to the evaporation of raw materials moisture during the agglomeration process. Since the iron ore quarries are located in both dray and wet areas of the country, the water content of their stones differ significantly, and should be taken into account as a part of the total annual purchasing cost.

\section{Annual purchasing cost (APC)}

Since ordering quantity $(Q)$ should be shared by $n=5$ suppliers, we have the following:

$$
\begin{gathered}
Q=\sum_{i=1}^{n} Q_{i} \quad Q_{i}=X_{i} Q \quad T_{i}=X_{i} T \quad 0 \leq X_{i} \leq 1 \\
\sum_{i=1}^{n} X_{i}=1 \quad i=1,2, \ldots, n
\end{gathered}
$$

Since annual purchasing from $i$ th supplier is $X_{i} D$ and its price is $P_{i}$, APC is:

$\mathrm{APC}=\sum_{i=1}^{n} X_{i} P_{i} D \quad i=1,2, \ldots, n$

\section{Annual transportation cost (ATC)}

ATC is computed by multiplying annual purchasing quantity, and transportation tariff, for $i$ th supplier, thus:

$\mathrm{ATC}=\sum_{i=1}^{n} X_{i} C_{t i} D \quad i=1,2, \ldots, n$

\section{Annual weight reduction cost (AWRC)}

As we mentioned earlier, the moisture content of receiving shipments from each supplier is significantly different.
Therefore, the weight reduction of materials due to evaporation in agglomeration process should be taken into account. The data for this is obtainable from Isfahan Steel works daily Lab Reports. Let $h_{i}$ be the average moisture fraction of $i$ th supplier, then, AWRC is computed as:

$\mathrm{AWRC}=\sum_{i=1}^{n} X_{i} D\left(h_{i}\right)\left(P_{i}+C_{t i}\right)=\sum_{i=1}^{n} X_{i} D h_{i}\left(P_{i}+C_{t i}\right)$

The above formula considers the fact that the evaporated moisture is actually bought and paid for its transportation.

To avoid unnecessary repetition, let $\beta_{i}$ be equal to $\left(P_{i}+C_{t i}\right)$ 1. Hence:

$\mathrm{AWRC}=\sum_{i=1}^{n} X_{i} D h_{i} \beta_{i} \quad i=1,2, \ldots, 5$

And, the sum of forgoing three costs is:

$$
\begin{aligned}
\mathrm{APC}+\mathrm{ATIC}+\mathrm{AWRC} & =\sum_{i=1}^{n} X_{i} D\left(1+h_{i}\right)\left(P_{i}+C_{t i}\right) \\
& =\sum_{i=1}^{n} X_{i} D\left(1+h_{i}\right) \beta_{i}
\end{aligned}
$$

Therefore, it is inferred that the unit cost of $i$ th supplier's material in agglomeration process is equal to $\left(1+h_{i}\right) \beta_{i}$. We will apply this formula to compute annual holding (carrying) cost.

\section{Annual holding cost (AHC)}

Referring to different behavior of inventory levels in Models $\mathrm{A}$ and $\mathrm{B}$, especially in regard with iron concentrate, obviously, the formulation of AHC differs slightly. To save us time, we proceed with formulating AHC for Model A only.

Average inventory in gradual receipt of shipments is equal to: $\frac{Q}{2}\left(1-\frac{D^{\prime}}{P^{\prime}}\right)+\mathrm{SS}$, or in general is $\frac{Q}{2}\left(1-\frac{D_{i}^{\prime}}{P_{i}^{\prime}}\right)+\mathrm{SS}_{i}$, so, the average holding cost in $T_{i}$ would be:

$$
\left(X_{i} \frac{Q}{2}\left(1-\frac{D_{i}^{\prime}}{P_{i}^{\prime}}\right)+\mathrm{SS}_{i}\right) r p_{i}
$$

In order to avoid unnecessary repetitions, let $\left(1-\frac{D_{i}^{\prime}}{P_{i}^{\prime}}\right)$ be equal to $\alpha_{i}$. Since SS is a constant value, it will be omitted in differentiation process any way. Thus, Total Holding Cost per Period (THCP) is formulated as follows:

$$
\begin{aligned}
\mathrm{THCP}= & X_{1} \frac{Q}{2} \alpha_{1} r\left(1+h_{1}\right) \beta_{1} T_{1}+X_{2} \frac{Q}{2} \alpha_{2} r\left(1+h_{2}\right) \beta_{2} T_{2} \\
& +\cdots+X_{n} \frac{Q}{2} \alpha_{n} r\left(1+h_{n}\right) \beta_{n} T_{n}
\end{aligned}
$$

In Model $\mathrm{A}$, for those suppliers that we have on hand inventory during the whole order cycle, $T_{i}=T$, $i=1,2, \ldots, m$, and for those vendors that we have on hand inventory just during a part of cycle, $T_{i}=\frac{X_{i}}{\sum_{i=m+1}^{n} X_{i}} T$, 
$i=m+1, \ldots, n$. Now, we know that $T=\frac{Q}{D}$, and considering the shape of the model, and the fact that $n=5$, we have:

$$
\begin{gathered}
T_{1}=T_{2}=T_{3}=T=\frac{Q}{D}, \quad T_{4}=\frac{X_{4}}{X_{4}+X_{5}} \frac{Q}{D}, \\
T_{5}=\frac{X_{5}}{X_{4}+X_{5}} \frac{Q}{D}
\end{gathered}
$$

(Here the flexibility and adoptability of the new models become clearer, as when the model, for any reason, does not allow purchase from supplier 4 , for instance, then, we have: $X_{4}=0, T_{4}=0$, and $T_{5}=T$ ).

However, the detailed computation of THCP is:

$$
\begin{aligned}
\mathrm{THCP}= & X_{1} \frac{Q}{2} \alpha_{1} r\left(1+h_{1}\right) \beta_{1} \frac{Q}{D}+X_{2} \frac{Q}{2} \alpha_{2} r\left(1+h_{2}\right) \beta_{2} \frac{Q}{D} \\
& +X_{3} \frac{Q}{2} \alpha_{3} r\left(1+h_{3}\right) \beta_{3} \frac{Q}{D} \\
& +X_{4} \frac{Q}{2} \alpha_{4} r\left(1+h_{4}\right) \beta_{4} \frac{X_{4}}{X_{4}+X_{5}} \frac{Q}{D} \\
& +X_{5} \frac{Q}{2} \alpha_{5} r\left(1+h_{5}\right) \beta_{5} \frac{X_{5}}{X_{4}+X_{5}} \frac{Q}{D}
\end{aligned}
$$

or

$$
\begin{aligned}
\mathrm{THCP}= & \sum_{i=1}^{3} X_{i} Q^{2} \frac{\alpha_{i} r\left(1+h_{i}\right) \beta_{i}}{2 D} \\
& +\frac{X_{4}^{2}}{X_{4}+X_{5}} Q^{2} \frac{\alpha_{4} r\left(1+h_{4}\right) \beta_{4}}{2 D} \\
& +\frac{X_{5}^{2}}{X_{4}+X_{5}} Q^{2} \frac{\alpha_{5} r\left(1+h_{5}\right) \beta_{5}}{2 D}
\end{aligned}
$$

Still, the shorter form for THCP is

$$
\begin{aligned}
\mathrm{THCP}= & \frac{r Q^{2}}{2 D}\left(\sum_{i=1}^{3} X_{i} \alpha_{i}\left(1+h_{i}\right) \beta_{i}\right) \\
& +\frac{r Q^{2}}{2 D} \frac{1}{\sum_{i=4}^{5} x_{i}}\left(\sum_{i=4}^{5} X_{i}^{2} \alpha_{i}\left(1+h_{i}\right) \beta_{i}\right)
\end{aligned}
$$

The Annual Holding Cost (AHC) is computed by multiplying THCP and the number of order cycles per year, or $\mathrm{AHC}=(\mathrm{THCP}) \times \frac{1}{T}=\frac{(\mathrm{THCP}) D}{Q}$

And with suitable substitutions, we have

$$
\begin{aligned}
\mathrm{AHC}= & \frac{r Q^{2}}{2 D}\left(\sum_{i=1}^{3} X_{i} \alpha_{i}\left(1+h_{i}\right) \beta_{i}\right) \frac{D}{Q} \\
& +\frac{r Q^{2}}{2 D} \frac{1}{\sum_{i=4}^{5} x_{i}}\left(\sum_{i=4}^{5} X_{i}^{2} \alpha_{i}\left(1+h_{i}\right) \beta_{i}\right) \frac{D}{Q}
\end{aligned}
$$

or, simply

$$
\begin{aligned}
\mathrm{AHC}= & \frac{r Q}{2}\left(\sum_{i=1}^{3} X_{i} \alpha_{i}\left(1+h_{i}\right) \beta_{i}\right) \\
& +\frac{r Q}{2} \frac{1}{\sum_{i=4}^{5} x_{i}}\left(\sum_{i=4}^{5} X_{i}^{2} \alpha_{i}\left(1+h_{i}\right) \beta_{i}\right)
\end{aligned}
$$

Also holding cost of Model B is:

$\mathrm{AHC}=\frac{r Q}{2}\left(\sum_{i=1}^{5} X_{i} \alpha_{i}\left(1+h_{i}\right) \beta_{i}\right)$

\section{Annual ordering cost (AOC)}

Due to the fact that the required raw materials are ordered and purchased from $n$ suppliers, the Ordering Cost each Period (OCP) is:

$\mathrm{OCP}=\sum_{i=1}^{n} A_{i} Y_{i}, \quad i=1,2, \ldots, 5$

where $Y_{i}=\left\{\begin{array}{ll}1 & \text { if } X_{i}>0 \\ 0 & \text { if } X_{i}=0\end{array} \quad i=1,2, \ldots, 5\right.$

AOC is obtained from multiplication of OCP by the number of periods per year:

$$
\begin{aligned}
\mathrm{AOC} & =(\mathrm{OCP}) \times \frac{1}{T} \Rightarrow \mathrm{AOC}=\left(\sum_{i=1}^{n} A_{i} Y_{i}\right) \frac{1}{T} \\
& =\left(\sum_{i=1}^{n} A_{i} Y_{i}\right) \frac{D}{Q}
\end{aligned}
$$

Having formulated the annual costs of purchased materials and AHC and AOC, the Total Annual Costs (TAC) is simply computed by adding up all these costs:

$$
\begin{aligned}
\mathrm{TAC}= & \mathrm{APC}+\mathrm{ATC}+\mathrm{AWRC}+\mathrm{AHC}+\mathrm{AOC} \\
\mathrm{TAC}= & \sum_{i=1}^{5} X_{i} P_{i} D+\sum_{i=1}^{5} X_{i} C_{t i} D+\frac{r Q}{2}\left(\sum_{i=1}^{3} X_{i} \alpha_{i}\left(1+h_{i}\right) \beta_{i}\right) \\
& +\frac{1}{\sum_{i=4}^{5} x_{i}} \times \frac{r Q}{2}\left(\sum_{i=4}^{5} X_{i}^{2} \alpha_{i}\left(1+h_{i}\right) \beta_{i}\right)+\frac{D}{Q}\left(\sum_{i=1}^{5} A_{i} Y_{i}\right) \\
& +\sum_{i=1}^{n} h_{i} \beta_{i} X_{i} D
\end{aligned}
$$

Manipulating the above equation a bit and considering that $\beta_{i}=P_{i}+C_{t i}$, a simpler from of TAC will be: 


$$
\begin{aligned}
\mathrm{TAC}= & \sum_{i=1}^{5} X_{i} D\left(1+h_{i}\right) \beta_{i}+\frac{r Q}{2}\left(\sum_{i=1}^{3} X_{i} \alpha_{i}\left(1+h_{i}\right) \beta_{i}\right)+\frac{1}{\sum_{i=4}^{5} x_{i}} \\
& \times \frac{r Q}{2}\left(\sum_{i=4}^{5} X_{i}^{2} \alpha_{i}\left(1+h_{i}\right) \beta_{i}\right)+\frac{D}{Q}\left(\sum_{i=1}^{5} A_{i} Y_{i}\right)
\end{aligned}
$$

As usual, we differentiate the above equation in respect to $Q$ to obtain the optimum order quantities. Doing so, we have:

$$
\begin{aligned}
(\mathrm{TAC})^{\prime}= & \frac{r}{2}\left(\sum_{i=1}^{3} X_{i} \alpha_{i}\left(1+h_{i}\right) \beta_{i}\right)+\frac{r}{2} \\
& \times \frac{1}{\sum_{i=4}^{5} X_{i}}\left(\sum_{i=4}^{5} X_{i}^{2} \alpha_{i}\left(1+h_{i}\right) \beta_{i}\right) \\
& -\frac{D}{Q^{2}}\left(\sum_{i=1}^{5} A_{i} Y_{i}\right)
\end{aligned}
$$

Finally, omitting $Q$, the objective function for Model A is:

$\mathrm{TAC}=\sum_{i=1}^{5} X_{i} D\left(1+h_{i}\right) \beta_{i}+\sqrt{2 D r\left(\sum_{i=1}^{3} X_{i} \alpha_{i}\left(1+h_{i}\right) \beta_{i}\right)+\frac{1}{\sum_{i=4}^{5} X_{i}}\left(\sum_{i=4}^{5} X_{i}^{2} \alpha_{i}\left(1+h_{i}\right) \beta_{i}\right) \times \sqrt{\sum_{i=1}^{5} A_{i} Y_{i}}}$

And the optimum order quantity, $Q^{*}$, is:

$$
Q^{*}=\sqrt{\frac{2 D\left(\sum_{i=1}^{n} A_{i} Y_{i}\right)}{r\left(\sum_{i=1}^{m} X_{i} \alpha_{i}\left(1+h_{i}\right) \beta_{i}\right)+\frac{1}{\sum_{i=m+1}^{n} X_{i}}\left(\sum_{i=1}^{n} X_{i}^{2} \alpha_{i}\left(1+h_{i}\right) \beta_{i}\right)}}
$$

the objective function for Model B after omitting $Q$ is:

$$
\begin{aligned}
\operatorname{Min} \mathrm{TAC}= & \sum_{i=1}^{5} X_{i} D\left(1+h_{i}\right) \beta_{i} \\
& +\sqrt{2 D r\left(\sum_{i=1}^{5} X_{i} \alpha_{i}\left(1+h_{i}\right) \beta_{i}\right)\left(\sum_{i=1}^{5} A_{i} Y_{i}\right)}
\end{aligned}
$$

And the optimum order quantity, $Q^{*}$, is:

$$
Q^{*}=\sqrt{\frac{2 D\left(\sum_{i=1}^{n} A_{i} Y_{i}\right)}{r\left(\sum_{i=1}^{n} X_{i} \alpha_{i}\left(1+h_{i}\right) \beta_{i}\right)}}
$$

\section{The model constraints}

The constraints of this model actually pertains to the buyer's annual demand and quality of receiving materials, on one hand, and the suppliers' allocable capacity, on the other. In the following section, we present formulation of these constraints, as they were introduced to the model:

\section{Demand constraint}

Assuring $D$ is the Isfahan works, annual demand for iron ore and iron concentrate, as we mentioned earlier, $n=5$ vendors can satisfy $D$ at the present time. Therefore, we have:

$\sum_{i=1}^{n} X_{i} D=D \quad i=1,2, \ldots, 5$

Omitting $D$ from both sides of equation, then we have: 
where $q_{\mathrm{aFe}}$ is the minimum acceptable percent of Fe in the input mix, and $q_{\mathrm{Fe} i}$ is the percent of Fe content in the $i$ th supplier's material.

Due to the assumptions of Model A, which requires breaking the order cycle into two parts, we should divide the Fe quality constraint into two parts as well, and introduce it to the model as follows:

$$
\begin{aligned}
& \left(X_{1} D q_{\mathrm{Fe} 1}+X_{2} D q_{\mathrm{Fe} 2}+X_{3} D q_{\mathrm{Fe} 3}\right. \\
& \left.\left.\quad+\left(1-X_{1}+X_{2}+X_{3}\right)\right) D q_{\mathrm{Fe} 4}\right) \geq D q_{\mathrm{aFe}} \\
& \left(X_{1} D q_{\mathrm{Fe} 1}+X_{2} D q_{\mathrm{Fe} 2}+X_{3} D q_{\mathrm{Fe} 3}\right. \\
& \left.\left.\quad+\left(1-X_{1}+X_{2}+X_{3}\right)\right) D q_{\mathrm{Fe} 5}\right) \geq D q_{\mathrm{aFe}} \\
& \quad \sum_{i=1}^{5} D X_{i} q_{\mathrm{Fe} i}-10^{20} Y_{4} D-10^{20} Y_{5} D \geq D q_{\mathrm{afe}}
\end{aligned}
$$

Knowing that:

$X_{4} \leq\left(1-\left(X_{1}+X_{2}+X_{3}\right)\right)$

$X_{5} \leq\left(1-\left(X_{1}+X_{2}+X_{3}\right)\right)$

And omitting $D$ from both sides, we have:

$\left.\left(X_{1} q_{\mathrm{Fe} 1}+X_{2} q_{\mathrm{Fe} 2}+X_{3} q_{\mathrm{Fe} 3}+\left(1-X_{1}+X_{2}+X_{3}\right)\right) q_{\mathrm{Fe} 4}\right) \geq q_{\mathrm{afe}}$

$\left.\left(X_{1} q_{\mathrm{Fe} 1}+X_{2} q_{\mathrm{Fe} 2}+X_{3} q_{\mathrm{Fe} 3}+\left(1-X_{1}+X_{2}+X_{3}\right)\right) q_{\mathrm{Fe} 5}\right) \geq q_{\mathrm{afe}}$

$\sum_{i=1}^{5} X_{i} q_{\mathrm{Fe} i}-10^{20} Y_{4}-10^{20} Y_{5} \geq q_{\mathrm{afe}}$

$X_{4} \leq\left(1-\left(X_{1}+X_{2}+X_{3}\right)\right)$

$X_{5} \leq\left(1-\left(X_{1}+X_{2}+X_{3}\right)\right)$

Additionally the number $10^{20}$ that represented is a very large number in the model.

Quality Constraint for Model B is:

$\sum_{i=1}^{5} X_{i} q_{\mathrm{Fe} i} \geq q_{\mathrm{aFe}}$

\section{Capacity constraint}

This constraint stems from the fact that the $i$ th supplier can satisfy only a fraction of the annual buyer's needs, $C_{i}$, each year. Thus: $X_{i} D \leq C_{i}$.

Finally, we have to make sure that $Y_{i}$ has an integer value of 0 or 1 . To introduce this constraint to model, and knowing that $X_{i}$ is always equal or less than 1, then we have:

$X_{i} \leq Y_{i} \quad i=1,2, \ldots, n$

$X_{i} \geq \varepsilon Y_{i}$

where, $\varepsilon$ is a little bit greater than 0 .

Instead, in above constraint formulas, where ever we have $X_{i}$, we can multiply it by $Y_{i}$.
Fe quality constraint

\section{Model A formulation}

Now, we summarize Model A formulation as follows:

$$
\begin{aligned}
& \operatorname{MinTAC}=\sum_{i=1}^{n} X_{i} D\left(1+h_{i}\right) \beta_{i}+\frac{r Q}{2}\left(\sum_{i=1}^{m} X_{i} \alpha_{i}\left(1+h_{i}\right) \beta_{i}\right) \\
& +\frac{1}{\sum_{i=m+1}^{n} X_{i}} \times \frac{r Q}{2}\left(\sum_{i=m+1}^{n} X_{i}^{2} \alpha_{i}\left(1+h_{i}\right) \beta_{i}\right)+\frac{D}{Q}\left(\sum_{i=1}^{n} A_{i} Y_{i}\right) \\
& \sum_{i=1}^{n} X_{i}=1 \quad i=1,2, \ldots, m, \ldots m+1, \ldots n \\
& \left(\sum_{i=1}^{m} X_{i} q_{\mathrm{Fe} i}+\left(1-\left(\sum_{i=1}^{m} X_{i}\right)\right) q_{\mathrm{Fe}(m+1)}\right) \geq q_{\mathrm{aFe}} Y_{m+1} \\
& \left(\sum_{i=1}^{m} X_{i} q_{\mathrm{Fe} i}+\left(1-\left(\sum_{i=1}^{m} X_{i}\right)\right) q_{\mathrm{Fe}(m+2)}\right) \geq q_{\mathrm{aFe}} Y_{m+2} \\
& \vdots \quad \vdots \quad \vdots \\
& \left(\sum_{i=1}^{m} X_{i} q_{\mathrm{Fe} i}+\left(1-\left(\sum_{i=1}^{m} X_{i}\right)\right) q_{\mathrm{Fe}(n)}\right) \geq q_{\mathrm{aFe}} y_{n} \\
& \sum_{i=1}^{n} X_{i} q_{\mathrm{Fe} i}-10^{20} \sum_{i=m+1}^{n} Y_{i} \geq q_{\mathrm{aFe}} \\
& 0 \leq X_{m+1} \leq\left(1-\left(\sum_{i=1}^{m} X_{i}\right)\right) \\
& 0 \leq X_{m+2} \leq\left(1-\left(\sum_{i=1}^{m} X_{i}\right)\right) \\
& \vdots \quad: \\
& 0 \leq X_{n} \leq\left(1-\left(\sum_{i=1}^{m} X_{i}\right)\right) \\
& X_{i} D \leq C_{i} \quad i=1,2, \ldots, n \\
& Q_{i}=X_{i} Q \\
& X_{i} \leq Y_{i} \\
& X_{i} \geq \varepsilon Y_{i} \\
& Q=\sum_{i=1}^{n} Q_{i} \\
& X_{i} \geq 0, Y_{i}=0,1, \quad i=1,2, \ldots, m, \ldots, n
\end{aligned}
$$

\section{Model B formulation}

We summarize Model $B$ formulation as follows: 


$$
\begin{aligned}
& \text { Min TAC }=\sum_{i=1}^{n} X_{i} D\left(1+h_{i}\right) \beta_{i}+\frac{r Q}{2}\left(\sum_{i=1}^{n} X_{i} \alpha_{i}\left(1+h_{i}\right) \beta_{i}\right) \\
& \quad+\frac{D}{Q}\left(\sum_{i=1}^{n} A_{i} Y_{i}\right) \\
& \sum_{i=1}^{n} X_{i}=1 \quad i=1,2, \ldots, n \\
& \sum_{i=1}^{n} X_{i} q_{\mathrm{Fe} i} \geq q_{\mathrm{aFe}} \quad i=1,2, \ldots, n \\
& X_{i} D \leq C_{i} \quad i=1,2, \ldots, n \\
& Q_{i}=X_{i} Q \\
& X_{i} \leq Y_{i} \\
& X_{i} \geq \varepsilon Y_{i} \\
& Q=\sum_{i=1}^{n} Q_{i} \\
& X_{i} \geq 0, Y_{i}=0,1, \quad i=1,2, \ldots, m . ., n
\end{aligned}
$$

\section{Parameters of model}

It should be considered that the model was tested for two time periods (two successive years). Some of the parameters are the same for two time period and others are different thus they are represented separately (Tables 2, 3).

Table 2 Common parameters for two successive years

\begin{tabular}{lllllr}
\hline$i$ & $r$ & $\alpha_{i}$ & $q_{\mathrm{Fe} i}$ & $h_{i}$ & \multicolumn{1}{c}{$C_{i}$} \\
\hline 1 & 0.16 & 0.685 & 60.19 & 0.0189 & $2,021,000$ \\
2 & 0.16 & 0.594 & 61.56 & 0.0434 & 142,000 \\
3 & 0.16 & 0.837 & 60.41 & 0.0773 & 84,000 \\
4 & 0.16 & 0.282 & 67.26 & 0.0915 & $3,000,000$ \\
5 & 0.16 & 0.084 & 68.06 & 0.0832 & $4,000,000$ \\
\hline
\end{tabular}

Table 3 Different parameters for two successive years

\begin{tabular}{llllll}
\hline$i$ & \multicolumn{2}{l}{ First year } & & \multicolumn{2}{l}{ Second year } \\
\cline { 2 - 3 } \cline { 5 - 6 } & $A_{i}$ & $\beta_{i}$ & & $A_{i}$ & $\beta_{i}$ \\
\hline 1 & $10,485,422$ & 157,682 & & $10,083,210$ & 122,000 \\
2 & $10,485,422$ & 170,000 & & $10,083,210$ & 128,000 \\
3 & $10,485,422$ & 198,000 & $10,083,210$ & 167,500 \\
4 & $10,485,422$ & 254,000 & & $10,083,210$ & 254,000 \\
5 & $10,485,422$ & 215,000 & & $10,083,210$ & 215,000 \\
\hline$q_{\text {a first year }}=61.17, q_{\text {a }}$ second year & $=60.23, D_{\text {first year }}=2,082,368$, \\
$D_{\text {second year }}=1,861,518$ & &
\end{tabular}

Table 4 Model A results

\begin{tabular}{lll}
\hline & First year & Second year \\
\hline Objective function (Rials) & $286,884,300,000$ & $300,929,000,000$ \\
$X_{1}$ & 0.8191556 & 0.9949174 \\
$X_{2}$ & 0.0681916 & 0 \\
$X_{3}$ & 0 & 0 \\
$X_{4}$ & 0 & 0 \\
$X_{5}$ & 0.1126528 & 0.005082592 \\
$Y_{1}$ & 1 & 1 \\
$Y_{2}$ & 1 & 0 \\
$Y_{3}$ & 0 & 0 \\
$Y_{4}$ & 0 & 0 \\
$Y_{5}$ & 1 & 1 \\
$Q$ & $100,844.4$ & $66,727.33$ \\
$Q_{1}$ & $82,640.02$ & $66,388.18$ \\
$Q_{2}$ & 6879.469 & 0 \\
$Q_{3}$ & 0 & 0 \\
$Q_{4}$ & 0 & 0 \\
$Q_{5}$ & $11,364.91$ & 339.1478 \\
\hline
\end{tabular}

\section{Model runs and results}

In order to run the formulated models and compare its results with actual performance, we had to compute model parameters from Company's records. This was done carefully using data of two consecutive financial years. We employed the global option of Lingo Version 8 for running the models. The results are summarized in Table 4 .

Take notice of the fact that the model has chosen three of the suppliers for the first year and only two of them in the second year. Exactly, the same results obtained when running Model B too. Obtaining the same results from Models A and B is rather exceptional, and relates only to this studied situation, and stems from the fact that both models rejected buying iron concentrate from a particular vendor. Models are based on important criteria such as cost, quality and capacity.

Actually, Isfahan Steel Co. on a regular basis, has been buying raw materials form all five suppliers during those 2 years. A comparison of the model results with the actual cost performance of the Company is made in Table 5.

\section{Discussion and conclusion}

Examining the results presented in Tables 4 and 5, reducing cost by 10.9 and $7.1 \%$, increasing company's annual profit, attract any top manager's attention. One might argue that real world mangers of large processing firms like Isfahan Steel Company keep purchasing from different sources to ensure a continuous and reliable stream of 
Table 5 Comparing the model results with actual data

\begin{tabular}{lll}
\hline Results & First year & Second year \\
\hline Total cost of the Model A & $286,884,300,000$ & $300,292,000,000$ \\
Total actual cost (Rials) & $321,929,098,600$ & $323,290,000,000$ \\
Cost reduction (Rials) & $35,044,798,600$ & $22,998,000,000$ \\
$\%$ of reduction & 10.9 & 7.1 \\
\hline
\end{tabular}

supplies. However, it turned out to be a very expensive way to get such assurances. The responsible managers of the said company had not been aware of the tremendous differences that a wrong suppliers selection decisions could create. Furthermore, one of the real potential values of mathematical modeling is reminding the mangers of alternative ways of doing their daily affairs.

However, some points should be mentioned about the new models and the present study:

1. The models determine the percentages of iron ore and iron concentrate to be mixed in agglomeration process. This is done by considering the minimum $\mathrm{Fe}$ contents required for specified output quality of the process, $q_{\text {afe }}$, and other constraints, and objective function. The models recommended a mix of $88.73472 \%$ iron ore and $11.26528 \%$, concentrate for the first year and $99.49174 \%$ iron ore, $0.005082592 \%$ concentrate for the second year.

2. A sensitivity analysis of the models was assumed by changing capacity and quality constraints' parameters, the number of placed orders in a year, $D / Q$. The results of the sensitivity analysis revealed that even in the most pessimistic conditions, the models would result in total costs reduction.

One of the interesting findings of the sensitivity analysis of the model was that if the second iron ore supplier had no capacity limitations, and could supply the Company's whole annual needs, a substantial costs reduction could happened. Based on this finding, we recommended the management helping that particular supplier to invest in increasing its capacity through a joint venture project.

3. The non-linear assumption of these models makes them closer to the real world managerial problems. Most of the relationships in socio-economic systems are non-linear in nature. Yet, Model B is flexible enough to be changed to a linear model simply by assuming $D / Q$ as constant. As a result, the new models are applicable to a fairly large area of operations management special problems.

4. The new models are not just a simple inventory model. As we have seen, the models can handle a multicriteria situation comprising cost and quality and help us select appropriate suppliers. They also can present a purchasing schedule to tell us when and how much to buy from each vendor. At the same time, the models can suggest an optimum consumption mix of the materials.

In summary, the new models presented in this article have notable advantages and improvements over the previously introduced ones, such as Ghodsypour and O'Brien model (2001), with a considerable number of real world special applications.

Open Access This article is distributed under the terms of the Creative Commons Attribution 4.0 International License (http://crea tivecommons.org/licenses/by/4.0/), which permits unrestricted use, distribution, and reproduction in any medium, provided you give appropriate credit to the original author(s) and the source, provide a link to the Creative Commons license, and indicate if changes were made.

\section{References}

Aissaouia N, Haouaria M, Hassinib E (2007) Supplier selection and order lot sizing modeling: a review. Comput Oper Res 34:3516-3540

Amid A, Ghodsypour SH, O’ Brein CO (2006) Fuzzy multiobjective linear model for supplier selection in a supply chain. Int $\mathrm{J}$ Prod Econ 104:394-407

Basnet C, Leung JMY (2005) Inventory lot-sizing with supplier selection. Comput Oper Res 32:1-14

Benton WC (1991) Quantity discount decision under conditions of multiple items, multiple suppliers and resource limitation. Int $\mathbf{J}$ Prod Econ 27:1953-1961

Chen C-T, Lin C-T, Huang S-F (2006) A fuzzy approach for supplier evaluation and selection in supply chain management. Int J Prod Econ 102(2):289-301

Dickson GW (1966) An analysis of vendor selection systems and management. J Purch 2(1):5-17

Farzipoor Saen R (2007) Suppliers selection in the presence of both cardinal and ordinal data. Eur J Oper Res 183:741-747

Ghodsypour SH, O'Brien C (1997) A decision support system for reducing the number of suppliers and managing the supplier partnership in a JIT/TQM environment. In: Proceedings of 3rd international symposium on logistics, University of Padua, Italy

Ghodsypour SH, O'Brien C (1998) A decision support system for supplier selection using an integrated analytic hierarchy process and linear programing. Int J Prod Econ 56-57:199-212

Ghodsypour SH, O'Brien C (2001) The total cost of logistics in supplier selection, under conditions of multiple souring, multiple criteria and capacity constraint. Int J Prod Econ 73:15-27

Jafarnezhad A, Esmaelian M, Rabieh M (2009) Evaluation and selection of supplier in supply chain in case of single sourcing with fuzzy approach. Manag Res Iran 12(4):127-153

Kumar M, Vrat P, Shankar R (2004) A fuzzy goal programming approach for vendor selection problem in a supply chain. Comput Ind Eng 46(69):58

Kuo RJ, Lin Y (2012) Supplier selection using analytic network process and data envelopment analysis. Int $\mathrm{J}$ Prod Res 50(11):2852-2863

Lin HT, Chang WL (2008) Order selection and pricing methods using flexible quantity and fuzzy approach for buyer evaluation. Eur $\mathbf{J}$ Oper Res 187:415-428 
Mendoza A, Ventura JA (2012) Analytical models for supplier selection and order quantity allocation. Appl Math Model 36:3826-3835

Nair NG (2002) Resource management. Vikas Publishing House, New Delhi

Rabieh M, Soukhakian MA, Jafarnezhad A (2008) Designing a nonlinear compatible model of supplier selection in case of multiple sourcing: a case study of Isfahan Steel Company. Iran J Trade Stud 12(45):57-83

Rao KN, Subbaiaha KV, Singh GVP (2013) Design of supply chain in fuzzy environment. J Ind Eng Int. 9:9. doi:10.1186/2251-712X9-9
Soukhakian MA, Rabieh M, Afsar A (2007) Designing a inventory control model with a consideration of total cost of logistics in case of multiple sourcing. J Soc Sci Humanit Shiraz Univ 26(150):75-94

Ustun O, Aktar Demirtas E (2008) An integrated multi-objective decision-making process for multi-period lot-sizing with supplier selection. Omega 36:509-521

Weber CA, Current JR, Benton WE (1991) Vendor selection criteria and methods. Eur J Oper Res 50:2-18

Wu T, Blackhurst J (2009) Supplier evaluation and selection: an augmented DEA approach. Int J Prod Res 47(16):4593-4608 